\title{
Expression profiles of carnosine synthesis-related genes in mice after ingestion of carnosine or $\beta$-alanine
}

\author{
Takayuki Miyaji ${ }^{*}$, Mikako Sato ${ }^{1}$, Hirohiko Maemura ${ }^{2}$, Yoshihisa Takahata ${ }^{1}$ and Fumiki Morimatsu ${ }^{1}$
}

\begin{abstract}
Background: Carnosine is a dipeptide that improves exercise performance. The carnosine synthesis mechanism through carnosine and $\beta$-alanine ingestion remains unclear. Therefore, we investigated the tissue distribution of carnosine synthase, ATP-grasp domain-containing protein-1 (ATPGD1) mRNA, and ATPGD1 and carnosine specific dipeptidase (CN1) gene expression profiles in mice that were given carnosine or $\beta$-alanine orally.

Methods: $d d Y$ mice (7-week-old) were randomly divided into three groups ( $n=6$ to 8 animals per group) and were orally given $2 \mathrm{~g} / \mathrm{kg}$ body weight of carnosine, $\beta$-alanine, or water. After 15, 30, 60, 120, 180, or $360 \mathrm{~min}$ of treatment, the tissues (brain, blood, liver, kidneys, olfactory bulbs, hindleg muscles) were collected. The obtained tissues measured the expression of ATPGD1 and CN1 genes using quantitative PCR methods.

Results: The ATPGD1 gene was expressed in muscle and to a lesser extent in brain. The expression of ATPGD1 in the vastus lateralis muscle increased significantly at $180 \mathrm{~min}(P=0.023)$ after carnosine ingestion and $60(P=0.023)$ and $180 \mathrm{~min}(P=0.025)$ after $\beta$-alanine ingestion. Moreover, the carnosine group showed a significantly increased renal expression of the $\mathrm{CN} 1$ gene 60 min after ingestion $(P=0.0015)$.
\end{abstract}

Conclusions: The ATPGD1 gene showed high expression levels in brain and muscle. The $\beta$-alanine or carnosine administration significantly increased ATPGD1 and CN1 expression in mice.

Keywords: Carnosine, $\beta$-alanine, Carnosine synthase, Carnosinase

\section{Background}

Carnosine ( $\beta$-alanyl-L-histidine) is a dipeptide abundant in mammalian skeletal muscles [1,2]. Various physiological actions have been ascribed to carnosine in muscle, including acting as an antioxidant [3], regulating $\mathrm{Ca}^{2+}$ sensitivity [4], protecting proteins against glycation by acting as a sacrificial peptide [5], and preventing the formation of protein-protein cross links by reacting with protein-carbonyl groups [6]. Primarily, carnosine with $\mathrm{pH}$ buffering capacity is widely used in the field of sports nutrition [7]. Because the dissociation exponent (pKa) of carnosine is $6.83[8,9]$, it is suggested that carnosine attenuates the reduction in blood $\mathrm{pH}$ by a large amount of $\mathrm{H}^{+}$originating from the dissociation of lactic acid during strenuous

\footnotetext{
* Correspondence: t.miyaj@@ipponham.co.jp

${ }^{1}$ Research and Development Center, Nippon Meat Packers, Inc., 3-3

Midorigahara, Tsukuba, Ibaraki, 300-2646, Japan

Full list of author information is available at the end of the article
}

exercise, and suppresses a loss of force [10]. At the same time, muscle carnosine contents are positively correlated with high-intensity exercise performance [11] and fast-twitch muscle fibers [12]. Increase of muscle carnosine predominantly was due to the ingestion of histidine-containing dipeptide (HCD) such as carnosine, anserine ( $\beta$-alanyl-1-methylhistidine) and balenine ( $\beta$-alanyl-3-methylhistidine) or $\beta$-alanine. Although $\beta$-alanine could also be synthesized from the degradation of uracil, there are no reports on the relation between carnosine synthesis and pyrimidine catabolism. So, the majority of the previous research relating to the ergogenic effects of elevated muscle carnosine content via chicken breast extract, high in HCD content or $\beta$-alanine supplementation was performed using mice, horses and humans [1317].

However, ingested carnosine is rapidly degraded by two forms of carnosinase (CN1, EC 3.4.13.20; and CN2, EC

\section{() Biomed Central}


3.4.13.18) [18]. In humans, the CN1 gene is expressed in liver and brain tissue, and the protein is found in serum and brain tissue. Since the human CN1 specifically degrades both carnosine and homocarnosine, carnosine is absent in human blood. Whereas, CN1 in other mammals such as rodents is localized in the kidney, and a considerable amount of carnosine is contained in the blood [19]. CN2, which is also a cytosolic non-specific dipeptidase, does not degrade homocarnosine, and exhibits a rather broad specificity towards various dipeptides. That is, ingestion of $\beta$-alanine or carnosine that was degraded by these carnosinases, was increased muscle carnosine and the increase of muscle carnosine may be involved in carnosine synthase. However, the details were not revealed.

Recently, carnosine synthase was purified from chicken pectoral muscle and identified as an ATP-grasp domain-containing protein 1 (ATPGD1) [20]. It has been reported that ATPGD1 synthesizes carnosine using ATP, and the substrate specificity toward $\beta$-alanine (carnosine) in the presence of ATP and L-histidine is 14-fold higher than that of $\gamma$-aminobutyrate (homocarnosine). To verify that ATPGD1 acts as a carnosine synthase in vivo, we investigated the tissue distribution of ATPGD1 mRNA, and ATPGD1 and CN1 expression profiles in response to carnosine or $\beta$-alanine administration using quantitative PCR analysis.

\section{Methods}

\section{Oral administration study in mice}

Animal experiments were performed in accordance with the guidelines for Animal Experiments at Nippon Meat Packers Inc. and using minimum number of mice that dictated by an ethics committee ( $n=6$ or 8 ). Male SPFbred ddY (6-week-old) mice were purchased from Japan SLC, Inc. (Shizuoka, Japan). The mice were maintained under specifically controlled environmental conditions, namely, a 12-h light-dark cycle, a temperature of $23^{\circ} \mathrm{C}$, and a relative humidity of $50 \%$. At 7 weeks of age, the mice were randomly assigned by body weight into three groups (pre-administration group, $\mathrm{n}=8$, body weight of $32.5 \mathrm{~g}$; water administration group, $\mathrm{n}=6$, body weight of $33.4 \mathrm{~g}$; carnosine administration group, $\mathrm{n}=6$ or 8 , body weight of $33.2 \mathrm{~g} ; \beta$-alanine administration group, $\mathrm{n}=6$, body weight of $34.0 \mathrm{~g}$ ) and were orally given $2 \mathrm{~g} / \mathrm{kg}$ body weight of carnosine (Hamari Chemicals Ltd., Osaka, Japan), $\beta$-alanine (Wako Pure Chemical Industries, Ltd., Osaka, Japan), or water (control). After 15, $30,60,120,180$, or $360 \mathrm{~min}$ of treatment, the mice were anesthetized with Forane (Abbott Japan Co. Ltd., Japan) and then the brain, blood, liver, kidneys, olfactory bulbs, soleus muscles and vastus lateralis muscles were collected. The collected tissues were weighed, rapidly frozen with liquid nitrogen, and stored at $-80^{\circ} \mathrm{C}$ until analysis.

\section{Extraction of total RNA}

The frozen tissue samples were homogenized in $0.75 \mathrm{ml}$ of Isogen (Nippon Gene Co. Ltd., Tokyo, Japan) and then mixed thoroughly with $0.15 \mathrm{ml}$ of chloroform. The mixture was centrifuged $(20,000 \times g$ for $5 \mathrm{~min})$, and then the aqueous phases were collected, and $0.4 \mathrm{ml}$ of isopropanol was added. The precipitated total RNA was recovered and washed with $70 \%(\mathrm{v} / \mathrm{v})$ ethanol. The purity and concentration of the total RNA thus obtained were confirmed using an Experion electrophoresis system (Bio-Rad Laboratories, Inc., California, USA) and a NanoDrop 1000 spectrophotometer (Thermo Fisher Scientific K. K., Massachusetts, USA).

\section{Construction of gene specific primers}

Gene specific primers were designed by using PrimerBLAST (http://www.ncbi.nlm.nih.gov/tools/primer-blast/). The primers used were as follows: for ATPGD1 (NM_134148), forward primer, 5'-CCCTGGCCTTCGACC TCTCTCCAT-3' and reverse primer, 5'-CGGCACTGG GGCCCATCCTTC-3' to yield a 164-bp product; for CN1 (NM_177450), forward primer, 5'-TGGTGGCATCCTCAACGAACCA-3' and reverse primer, 5' ${ }^{\prime}$-TCCAGGAAT'TAGGATGTGGCCTGA-3' to yield an 88-bp product; for $\beta$-actin (NM_007393), forward primer, 5' -ATGAGCTG CCTGACGGCCAGGTCATC-3' and reverse primer, 5' TGGTACCACCAGACAGCACTGTGTTG-3' to yield a 192-bp product.

\section{Quantification of mRNA levels}

cDNA was synthesized by using a PrimeScript RT reagent Kit with gDNA Eraser (Takara Bio, Inc., Shiga, Japan). The genomic DNA in the RNAs extracted from tissues was eliminated with gDNA Eraser, which were then reverse-transcribed by PrimeScript RT. Each $25 \mu \mathrm{l}$ of the PCR reaction mix contained a $2 \mu$ l template, $0.2 \mu \mathrm{M}$ of each primer, and $1 \times$ ROX Reference Dye II in $1 \times$ SYBR Premix Ex Taq II (Takara Bio, Inc.). The reaction was performed at $95^{\circ} \mathrm{C}$ for $30 \mathrm{~s}$; this was followed by 40 cycles at $95^{\circ} \mathrm{C}$ for $5 \mathrm{~s}$ and at $60^{\circ} \mathrm{C}$ for $20 \mathrm{~s}$. The fluorescence was measured at the end of the extension step in each cycle. Following cycling, a melt curve analysis was performed after each quantitative PCR to ensure that a single product had been amplified per primer set. The fold-change of the gene expression was calculated using the $2^{-\Delta \Delta \mathrm{Ct}}$ method with $\beta$-actin as an internal control. Student's $t$-test was used $(P<0.05$ or $P<0.01)$ to test statistical significance. 


\section{Detection of carnosine in muscle and blood}

Vastus lateralis muscle samples were deproteinized with $1 \mathrm{ml}$ of $5 \%(\mathrm{w} / \mathrm{v})$ sulfosalicylic acid. The samples were centrifuged at $20,000 \times g$ for $5 \mathrm{~min}$, and then the supernatants were filtered with a $0.45-\mu \mathrm{m}$ filter. Blood samples were dissolved in $1 \mathrm{M}$ perchloric acid (final concentration, $0.3 \mathrm{M}$ ) and centrifuged at $20,000 \times g$ for $5 \mathrm{~min}$. $\mathrm{KOH}(3 \mathrm{M})$ was added to the supernatants to realize a final concentration of $4.25 \% \mathrm{v} / \mathrm{v}$. After centrifugation $(20,000 \times g$ for $5 \mathrm{~min})$, the obtained supernatants were filtered and applied to a TSKgel ODS-80Ts column (Tosoh Co., Tokyo, Japan) equilibrated with $4 \%(\mathrm{v} / \mathrm{v})$ acetonitrile, $100 \mathrm{mM}$ sodium 1-pentanesulfonate, and $200 \mathrm{mM}$ ammonium dihydrogen phosphate $(\mathrm{pH} 2.0)$. The carnosine was eluted with the same buffer, and absorbance was detected at a wavelength of $214 \mathrm{~nm}$. Statistical analysis was performed with Tukey-Kramer test $(P<0.05$ or $P<0.01)$.

\section{Results}

\section{Tissue distribution of ATPGD1 mRNA}

The localization of ATPGD1 mRNA from various tissue samples was investigated by quantitative PCR methods. ATPGD1 genes were detected in muscle, a few in brain, and hardly in liver and kidney. The expression of ATPGD1 was 10.2-fold higher in the vastus lateralis muscle, 6.3 -fold higher in the soleus muscle and 1.8-fold higher in the brain than in the olfactory bulbs. In contrast, the expression of ATPGD1 in the liver and kidney was only $50 \%$ of that in the olfactory bulbs (Figure 1).

\section{Carnosine content of blood and muscle}

In mice that had ingested carnosine or $\beta$-alanine, we measured the carnosine content of the blood and vastus

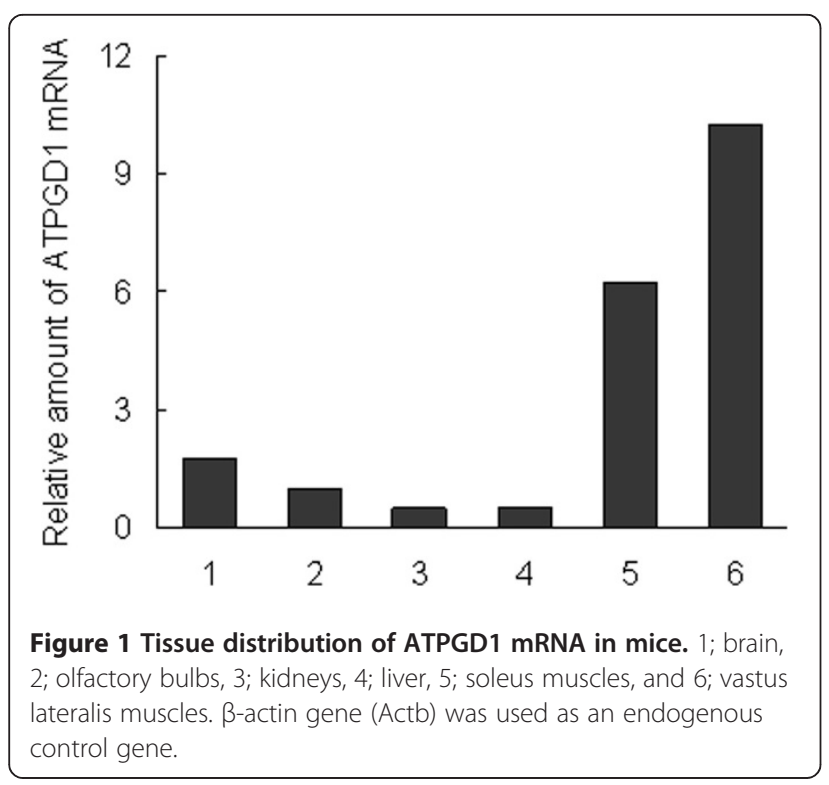

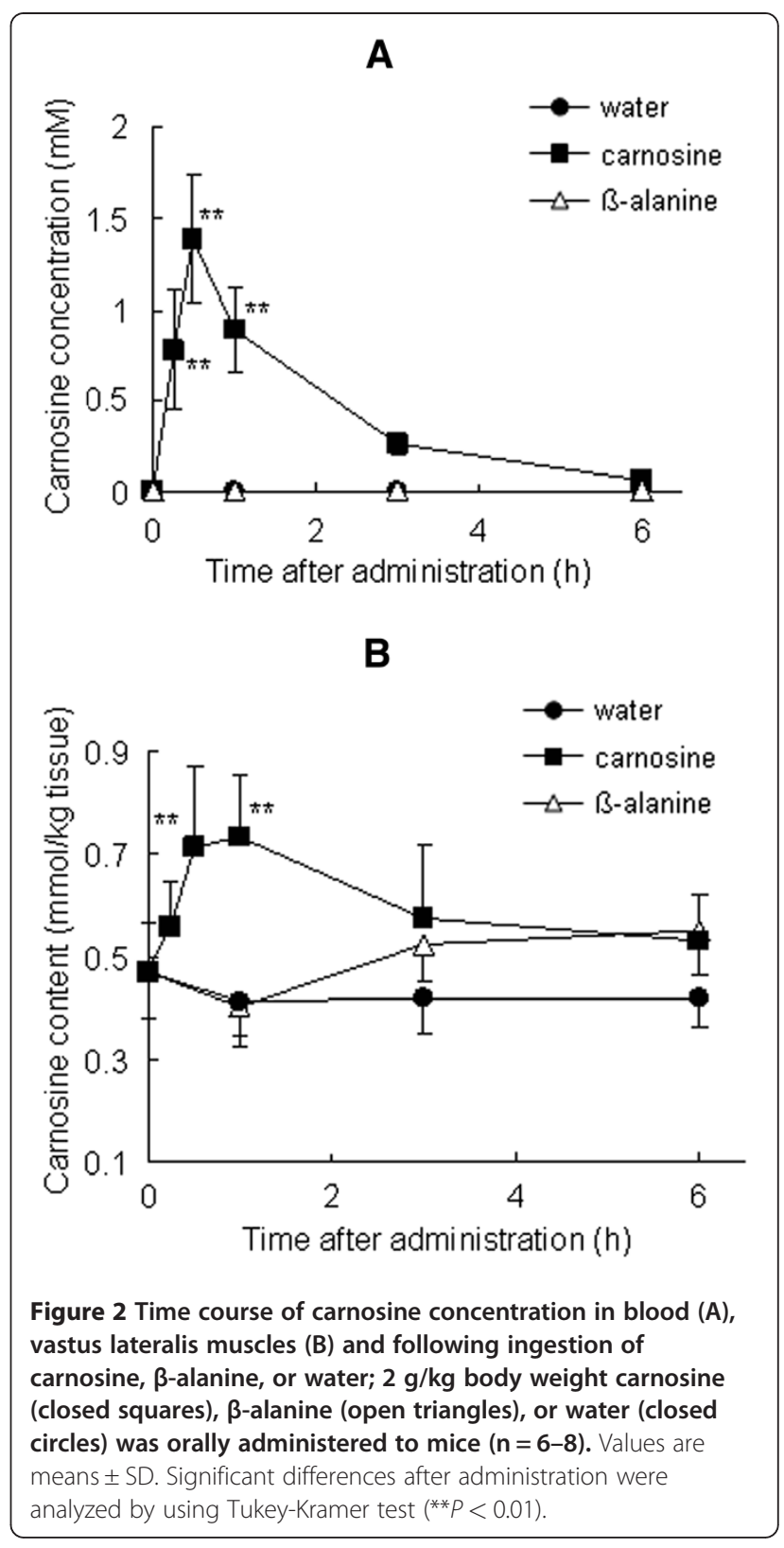

lateralis muscle by using an ODS-80Ts column. The carnosine content of the blood had significantly increased by 15 min after carnosine administration $(P<0.01)$; it peaked at $30 \mathrm{~min}(1.4 \pm 0.3 \mathrm{mM}, P<0.01)$ and had nearly disappeared by 6 h (Figure 2A). No carnosine was detected in the blood of the groups that ingested $\beta$-alanine or water. As shown Figure 2B, the carnosine content of the vastus lateralis muscle was $0.47 \pm 0.09 \mathrm{mmol} / \mathrm{kg}$ tissue before administration. The carnosine level had increased significantly 30 to $60 \mathrm{~min}$ after it was administered $(0.71 \pm$ $0.15 \mathrm{mmol} / \mathrm{kg}$ tissue at $30 \mathrm{~min}, P<0.01$ and $0.74 \pm$ $0.12 \mathrm{mmol} / \mathrm{kg}$ tissue at $60 \mathrm{~min}, P<0.01$ ) and then gradually decreased. The carnosine content of muscle in the 
group that ingested $\beta$-alanine did not increase significantly compared with that before administration $(P>0.05)$.

\section{Gene expression of ATPGD1 and CN1}

The expression profiles of carnosine synthesis-related genes were measured by using quantitative PCR. The ATPGD1 mRNA level in the vastus lateralis muscle was significantly elevated $3 \mathrm{~h}$ after carnosine administration $(P=0.023)$ and at $1(P=0.023)$ and $3 \mathrm{~h}(P=0.025)$ after $\beta$-alanine administration, compared with the level before administration. Expression increased from 2.7 to 3.2 times that before ingestion (Figure 3). After carnosine ingestion, the $\mathrm{CN} 1$ expression in the kidney peaked at $1 \mathrm{~h}$ and was significantly greater (3.6 times, $P=0.0015)$ than before ingestion (Figure 4).

\section{Discussion}

Carnosine synthase have been tried to purify from various sources [21-24] and Drozak et al. purified carnosine synthase from chicken pectoral muscle and the enzyme identified as ATPGD1, which is a member of the ATP-grasp family [20]. This paper was investigated about whether ATPGD1 involved in carnosine synthesis in mice.

Firstly, the tissue distribution of the ATPGD1 gene was investigated. The ATPGD1 gene was expressed more in brain and muscle than in olfactory bulbs, liver and kidney and particularly in the vastus lateralis muscle. The expression of the ATPGD1 gene was 1.6-fold higher than that in the soleus muscle. The carnosine content in the vastus lateralis muscle $(0.47 \mathrm{mmol} / \mathrm{kg}$ tissue $)$ was higher than in the soleus muscle $(0.35 \mathrm{mmol} / \mathrm{kg}$ tissue, $P=0.007$, data not shown), indicating that the ATPGD1 mRNA level depends on the carnosine content.

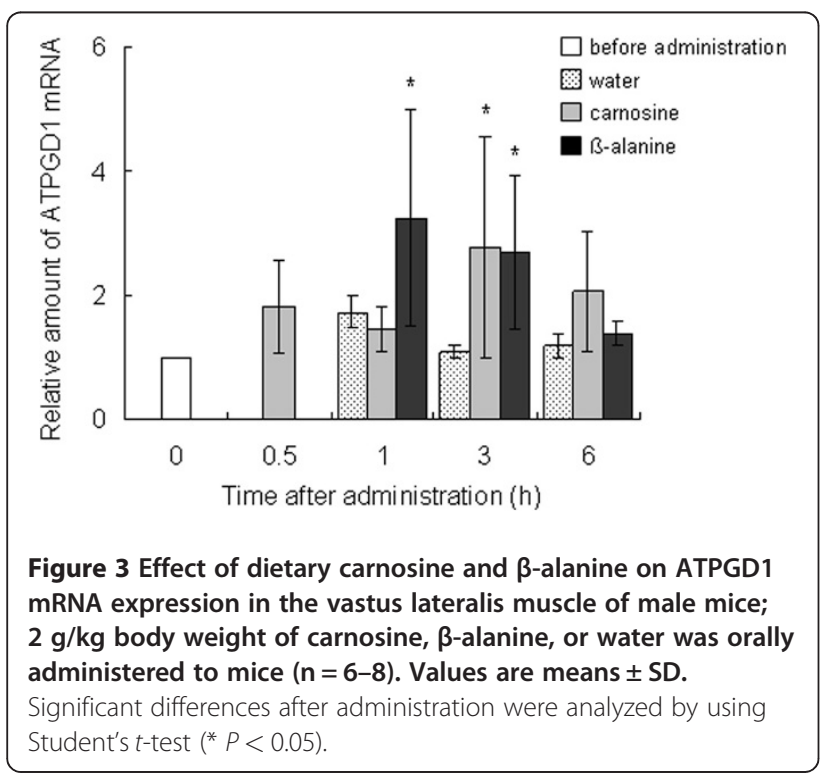

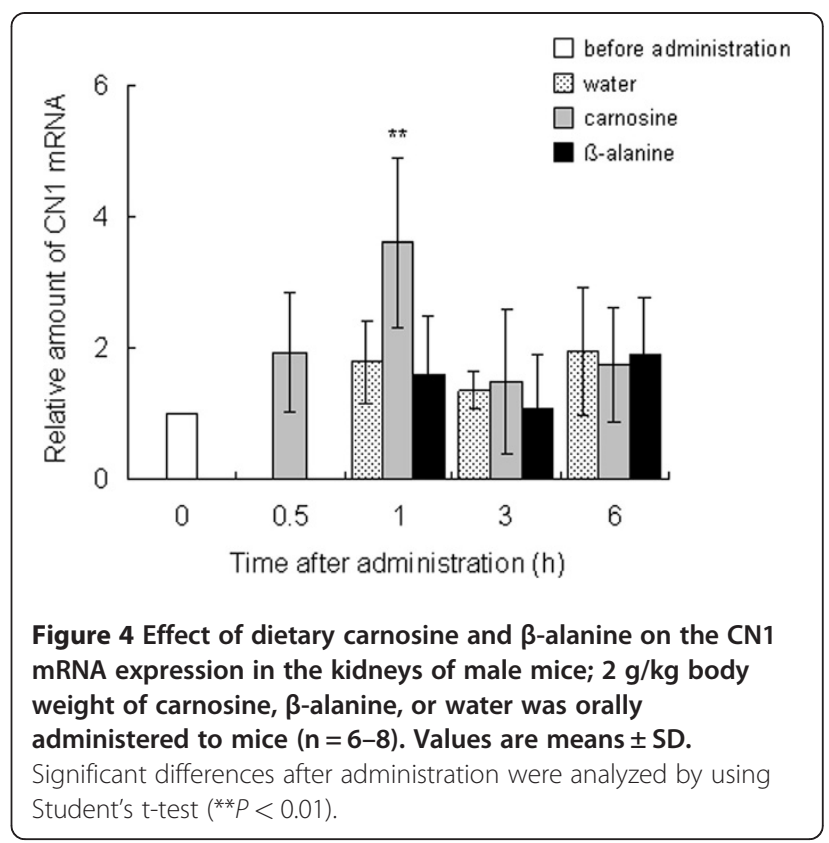

Secondly, we investigated the carnosine content and the expression of carnosine synthesis-related genes after the ingestion of carnosine or $\beta$-alanine. The carnosine supplementation group increased the carnosine content in blood and muscle and the expression of CN1 in the kidneys. Carnosine was injected into the tail vein of proton-coupled oligopeptide transporter PEPT2 knockout mice and the kidney/plasma concentration ratio of carnosine in the PEPT2 null mice was one-sixth that in wildtype [25]. Thus, it was considered that the ingested carnosine was eliminated from the serum by filtration into the urine and reabsorption into the kidney, and the reabsorbed carnosine increased the expression of CN1 in the kidney and would be hydrolyzed to $\beta$-alanine. Carnosine and $\beta$-alanine administration increased the ATPGD1 gene levels in the vastus lateralis muscles. This suggests that the hydrolyzed $\beta$-alanine in kidney increased ATPGD1 gene expression. Recently, Baguet et al. investigated the expression of ATPGD1 mRNA in human skeletal muscle. Twenty omnivorous subjects were randomly divided into a vegetarian and a mixed diet group, and took part in a five-week sprint training intervention (2-3 times per week). The ATPGD1 mRNA expression in the vegetarian diet group was decreased to $60 \%(P=0.023)$ by five weeks of sprint training [26]. This is consistent with our result showing that $\beta$-alanine is an important factor in ATPGD1 expression.

Chronic chicken breast extract or $\beta$-alanine supplementation leads to improved performance in high-intensity exercise $[27,28]$. However, the loading of carnosine takes at least several weeks [29], in contrast to the initial loading phase of one week for creatine [30]. This paper suggests that ATPGD1 acts as a carnosine synthase in mice, 
and provides new insights to determine efficient muscle carnosine loading.

\section{Conclusions}

The present study shows that the ATPGD1 mRNA in mice was expressed highly in brain and muscle, moderately in olfactory bulbs, scarcely in liver and kidneys, and approximately $67 \mathrm{mg}$ of $\beta$-alanine or carnosine administration in mice significantly increased ATPGD1 and CN1 expression.

\section{Competing interests}

The authors declare that they have no competing interests.

\section{Author details}

${ }^{1}$ Research and Development Center, Nippon Meat Packers, Inc., 3-3 Midorigahara, Tsukuba, Ibaraki, 300-2646, Japan. ${ }^{2}$ Department of Physical Education, International Pacific University, 721 Kannonji seto-cho, Higashi-ku, Okayama, 709-0863, Japan.

\section{Authors' contributions}

TM is the principal investigator of the project. MS, HM, YT and FM designed the study; MS and HM collected the data; YT and FM conducted data analysis; TM, MS and HM wrote the manuscript. All authors have read and approved the final manuscript.

Received: 14 September 2011 Accepted: 17 April 2012 Published: 17 April 2012

\section{References}

1. Crush KG: Carnosine and related substances in animal tissues. Comp Biochem Physiol 1970, 34:3-30.

2. Harris RC, Marlin DJ, Dunnett M, Snow DH, Hultman E: Muscle buffering capacity and dipeptide content in the thoroughbred horse, greyhound dog and man. Comp Biochem Physiol A Physiol 1990, 97:249-251.

3. Boldyrev AA, Koldobski A, Kurella E, Maltseva V, Stvolinski S: Natural histidine-containing dipeptide carnosine as a potent hydrophilic antioxidant with membrane stabilizing function. A biomedical aspect. Mol Chem Neuropathol 1993, 19:185-192

4. Batrukova MA, Rubtsov AM: Histidine-containing dipeptides as endogenous regulators of the activity of sarcoplasmic reticulum Carelease channels. Biochim Biophys Acta 1997, 1324:142-150.

5. Hipkiss AR, Michaelis J, Syrris P: Non-enzymatic glycosylation of the dipeptide L-carnosine, a potential anti-protein-cross-linking agent. FEBS Lett 1995, 371:81-85.

6. Hipkiss AR: Carnosine and protein carbonyl groups: a possible relationship. Biochemistry (Mosc) 2000, 65:771-778.

7. Derave W, Everaert I, Beeckman S, Baguet A: Muscle carnosine metabolism and beta-alanine supplementation in relation to exercise and training. Sports Med 2010, 40:247-263.

8. Smith EC: The buffering of muscle in rigor; protein, phosphate and carnosine. J Physiol 1938, 92:336-343.

9. Tanokura M, Tasumi M, Miyazawa T: ${ }^{1} \mathrm{H}$ nuclear magnetic resonance studies of histidine-containing di- and tripeptides, Estimation of the effects of charged groups on the pKa value of the imidazole ring. Biopolymers 1976, 15:393-401.

10. Baguet A, Koppo K, Pottier A, Derave W: Beta-alanine supplementation reduces acidosis but not oxygen uptake response during high-intensity cycling exercise. Eur J Appl Physiol 2010, 108:495-503.

11. Suzuki Y, Ito O, Mukai N, Takahashi H, Takamatsu K: High level of skeletal muscle carnosine contributes to the latter half of exercise performance during 30-s maximal cycle ergometer sprinting. Jpn J Physiol 2002, 52:199-205.

12. Baguet A, Everaert I, Hespel P, Petrovic M, Achten E, Derave W: A new method for non-invasive estimation of human muscle fiber type composition. PLoS One 2011, 6:e21956.
13. Harada R, Taguchi Y, Urashima K, Sato M, Ohmori T, Morimatsu F: Enhancement of swimming endurance in mice by chicken breast extract. J Jpn Soc Nutr Food Sci (in Japanese) 2002, 55:73-78.

14. Dunnett M, Harris RC: Influence of oral beta-alanine and L-histidine supplementation on the carnosine content of the gluteus medius. Equine Vet J Suppl 1999, 30:499-504.

15. Sato M, Suzuki Y, Morimatsu F, Takamatsu K: Effect of carnosine concentration in muscle and improvement of exercise performances due to long-term intake of chicken breast extract. Jpn J Phys Fitness Sports Med (in Japanese) 2003, 52:255-264.

16. Harris RC, Tallon MJ, Dunnett M, Boobis L, Coakley J, Kim HJ, Fallowfield JL, Hill CA, Sale C, Wise JA: The absorption of orally supplied beta-alanine and its effect on muscle carnosine synthesis in human vastus lateralis. Amino Acids 2006, 30:279-289.

17. Sale C, Saunders B, Harris RC: Effect of beta-alanine supplementation on muscle carnosine concentrations and exercise performance. Amino Acids 2010, 39:321-333.

18. Teufel M, Saudek V, Ledig JP, Bernhardt A, Boularand S, Carreau A, Cairns NJ, Carter C, Cowley DJ, Duverger D, Ganzhorn AJ, Guenet C, Heintzelmann B, Laucher V, Sauvage C, Smirnova T: Sequence identification and characterization of human carnosinase and a closely related non-specific dipeptidase. J Biol Chem 2003, 278:6521-6531.

19. Sauerhöfer S, Yuan G, Braun GS, Deinzer M, Neumaier M, Gretz N, Floege J, Kriz W, van der Woude F, Moeller MJ: L-Carnosine, a substrate of carnosinase-1, influences glucose metabolism. Diabetes 2007, 56:2425-2432.

20. Drozak J, Veiga-da-Cunha M, Vertommen D, Stroobant V, Schaftingen EV: Molecular identification of carnosine synthase as ATP-grasp domaincontaining protein 1 (ATPGD1). J Biol Chem 2010, 285:9346-9356.

21. Kalyankar GD, Meister A: Enzymatic synthesis of carnosine and related beta-alanyl and gamma-aminobutyryl peptides. J Biol Chem 1959, 234:3210-3218.

22. Stenesh JJ, Winnick T: Carnosine-anserine synthetase of muscle. 4. Partial purification of the enzyme and further studies of beta-alanyl peptide synthesis. Biochem J 1960, 77:575-581.

23. Skaper SD, Das S, Marshall FD: Some properties of a homocarnosinecarnosine synthetase isolated from rat brain. J Neurochem 1973, 21:14291445.

24. Horinishi $\mathrm{H}$, Grillo M, Margolis FL: Purification and characterization of carnosine synthetase from mouse olfactory bulbs. J Neurochem 1978, 31:909-919.

25. Kamal MA, Jiang H, Hu Y, Keep RF, Smith DE: Influence of genetic knockout of Pept2 on the in vivo disposition of endogenous and exogenous carnosine in wild-type and Pept2 null mice. Am J Physiol Regul Integr Comp Physiol 2009, 296:986-991.

26. Baguet A, Everaert I, Naeyer HD, Reyngoudt H, Stegen S, Beeckman S, Achten E, Vanhee L, Volkaert A, Petrovic M, Taes Y, Derave W: Effects of sprint training combined with vegetarian or mixed diet on muscle carnosine content and buffering capacity. Eur J Appl Physiol 2011, 111:2571-2580

27. Maemura H, Goto K, Yoshioka T, Sato M, Takahata Y, Morimatsu F, Takamatsu K: Effects of Carnosine and Anserine Supplementation on Relatively High Intensity Endurance Performance. International Journal of Sport and Health Science 2006, 4:86-94.

28. Derave W, Ozdemir MS, Harris RC, Pottier A, Reyngoudt H, Koppo K, Wise JA, Achten E: beta-Alanine supplementation augments muscle carnosine content and attenuates fatigue during repeated isokinetic contraction bouts in trained sprinters. J Appl Physiol 2007, 103:1736-1743.

29. Hill CA, Harris RC, Kim HJ, Harris BD, Sale C, Boobis LH, Kim CK, Wise JA: Influence of beta-alanine supplementation on skeletal muscle carnosine concentrations and high intensity cycling capacity. Amino Acids 2007, 32:225-233.

30. Casey A, Greenhaff PL: Does dietary creatine supplementation play a role in skeletal muscle metabolism and performance? Am J Clin Nutr 2000, 72:6075-6175

doi:10.1186/1550-2783-9-15

Cite this article as: Miyaji et al: Expression profiles of carnosine synthesis-related genes in mice after ingestion of carnosine or $\beta$-alanine. Journal of the International Society of Sports Nutrition 2012 9:15. 